\title{
LA ELECCIÓN DEL PARLAMENTO ITALIANO ENTRE LOS LÍMITES CONSTITUCIONALES Y LAS EXIGENCIAS DE LA POLÍTICA
}

\author{
GIAMPIETRO FERRI
}

doi: 10.18543/ed-64(2)-2016pp15-42

\begin{abstract}
Sumario: 1. LAS INDICACIONES DE LA ASAMBlEa CONSTITUYENTE SOBRE LA ELECCIÓN DE LAS CÁMARAS: «ORDEN DEL DÍA GIOLITTI» Y «ORDEN DEL DÍA NITTI». 2. LA RELACIÓN ENTRE LA CONSTITUCIÓN Y LOS SISTEMAS ELECTORALES DE LAS CÁMARAS. 3. El SISTEMA PROPORCIONAL EN LA PRIMERA FASE DE LA HISTORIA REPUBLICANA. 4. LOS SISTEMAS ELECTORALES MAYORITARIOS INTRODUCIDOS POR LAS LEYES N ${ }^{\circ} 276$ $\mathrm{Y} \mathrm{N}^{\circ} 277 / 1993$. 5. LA LEY N ${ }^{\circ} 270 / 2005$. 6. LA SENTENCIA DE LA CORTE CONSTITUCIONAL N ${ }^{\circ} 1 / 2014$. 7. LA LEY N ${ }^{\circ}$ 52/2015 SOBRE LA ELECCIÓN DE LA CÁMARA DE Diputados («ITALICUM»). 8. LA LEY ELECTORAL DE la Cámara de Diputados y el SEnado: ¿UNA Posible situación de INCONSTITUCIONALIDAD? 9. OBSERVACIONES FINALES SOBRE LAS RECIENTES PROPUESTAS PARA LA MODIFICACIÓN DEL «ITALICUM».
\end{abstract}

1. LAS INDICACIONES DE LA ASAMBLEA CONSTITUYENTE SOBRE LA ELECCIÓN DE LAS CÁMARAS: «ORDEN DEL DÍA GIOLITTI»Y «ORDEN DEL DÍA NITTI»

El Parlamento italiano, según la actual Constitución, es elegido por sufragio universal directo.

La Constitución no indica, sin embargo, cómo elegir las dos Cámaras del Parlamento (la Cámara de Diputados y el Senado).

La Asamblea Constituyente, elegida el 2 de junio de 1946, se refirió a la posibilidad de incluir en la Constitución indicaciones sobre la elección de las 
Cámaras, aunque prevaleció la voluntad de excluir cualquier referencia a ese tema. Esto no porque los constituyentes fueran indiferentes a la cuestión. De hecho, con la aprobación del «orden del día Giolitti», se pronunciaron a favor de la adopción en la Cámara de Diputados, del sistema proporcional, lo que garantiza la igualdad del voto «de salida», mejor que otros se adaptaba a la política del tiempo. Se trataba de una sociedad marcada por divisiones muy profundas, donde no se sentía necesidad para asegurar mayorías de gobierno estables, sino para construir un sistema eficaz de garantías, lo que limitaba el poder de los más fuertes ${ }^{1}$.

La indicación a favor de la representación proporcional, en lugar de la expresión de una preferencia por un sistema electoral, sin embargo, fue la elección de «una forma de organización política del Estado» ${ }^{2}$. La atribución a todos los partidos políticos de una representación parlamentaria en proporción a los votos obtenidos se consideraba de hecho esencial para la democracia misma. No se podía imaginar una «República democrática» (artículo n. ${ }^{\circ} 1$ de la Constitución) sin un parlamento que reflejase la realidad del país.

Los Constituyentes no pensaban, sin embargo, que la tendencia al proporcional habría permanecido para siempre sin cambios, y por eso no quisieron limitar el legislador: tanto para la elección de la Cámara y al Senado, en la que se aprobó un orden del día diferente, según el cual la elección se llevaría a cabo con la «circunscripción uninominal» (llamado «orden del día Nitti»).

Debido a que la circunscripción uninominal, que en sí mismo no se refiere a un sistema electoral, sino a una distribución territorial de los escaños, se acompaña en la mayoría de los casos a sistemas electorales mayoritarios (consideremos, por ejemplo, la elección de las Cámaras en los Estados Unidos); y puesto que en la monarquía la circunscripción uninominal fue

${ }^{1}$ M. LUCIANI, Il voto e la democrazia. La questione delle riforme elettorali in Italia (Roma, 1991), 21 ss., opina que el sistema proporcional responde a tres importantes objetivos: a) permitir el acceso a la representación parlamentaria de todas las fuerzas de la Resistencia; b) proporcionar «garantías mutuas» a las partes con vistas a un cambio posible de las relaciones de poder; c) «reforzar el papel de los partidos de masas [...] en la canalización de consenso y en la estructuración de la representación política». Observó además que, más que proporcionalmente, es el sistema de listas que «pone a los partidos de masas en el medio de la elección, rompiendo el vínculo entre el elector y el candidato típico de la circunscripción uninominal, fortalece el vínculo con el partido, arrancando las raíces de la notabilidad». Pero hay que tener en cuenta -sigue el Autor-que, en el debate en la Asamblea Constituyente, el proporcional «se hizo coincidir con el sistema de listas que compiten». La «opción proporcional - concluye el Autor-se convirtió, por lo tanto, al mismo tiempo, en opción para el sistema de listas».

2 Véase la intervención realizada por el Sr. Costantino Mortati en la sesión de la Segunda Subcomisión de la Comisión para la constitución de la Asamblea Constituyente de 7 de noviembre 1946. 
identificada con el sistema electoral, siendo los escaños de la Cámara asignados a los candidatos más votados en circunscripciones individuales, la interpretación más plausible del orden del día, es que sugiera al sistema mayoritario ${ }^{3}$.

Sin embargo, la reconstrucción del debate entre los constituyentes, no teniendo curso lineal, no permite afirmar que la actitud predominante fuese en este sentido, y, por lo tanto, que hayan querido negar la elección del Senado a favor de la representación proporcional ${ }^{4}$.

La ley electoral aprobada por el Senado de la misma Asamblea Constituyente, siempre que los colegios individuales en el escaño se concedan a los alumnos que han alcanzado el $65 \%$ de los votos válidos (un umbral casi imposible de lograr), marcará esencialmente la afirmación del principio proporcional $^{5}$, con la redistribución de los escaños no asignados en «listas» vinculadas a los candidatos individuales dentro de la región.

\section{LA RELACIÓN ENTRE LA CONSTITUCIÓN Y LOS SISTEMAS ELECTORALES DE LAS CÁMARAS}

La doctrina jurídica ha cuestionado la relación entre la Constitución y los sistemas electorales de las Cámaras.

En el discurso de apertura de la conferencia «Il sistema elettorale nella Costituzione italiana», que tuvo lugar a la Universidad de Macerata el 29 de noviembre de 1952, Carlo Lavagna había argumentado que los sistemas mayoritarios están prohibidos por la Constitución ${ }^{6}$.

Los sistemas mayoritarios «absolutos» que se caracterizan por el hecho de que el cuerpo electoral «se reúne en un solo colegio nacional para elegir a

${ }^{3}$ M. Pedrazza Gorlero, Il patto costituzionale. Potere e diritto fra protezione ed obbedienza (Padova, 2012), 178, habla de una opción para el «mayoritario». V. ONIDA, Costituzione. Perché difenderla, come riformarla (Roma, 1995), 21, se destaca que los constituyentes, que se aprueban dos programas separados, «empezaron con la idea» de que las dos Cámaras «iban a tener muy diferentes sistemas electorales»: proporcional y mayoritario, a condición de que las «circunscripciones uninominales» indiquen «un sistema [...] por sí mismo normalmente mayoritario» (véase V. ONIDA, La Costituzione (Bologna, 2004), 129.

${ }_{4}$ Excluyen que la opción proporcional de los Constituyentes, manifestada en la aprobación del «orden del día Giolitti», haya sido desconocida en el debate sobre la elección del Senado: G. Amato y F. Bruno, La forma di governo italiana. Dalle idee dei partiti all'Assemblea costituente, en Scritti in onore di Egidio Tosato, III (Milano, 1984), 48 y M. LUCIANI, Il voto e la democrazia, cit., 23 ss.

5 Véase, en este sentido, M. LUCIANI, Riforme elettorali e disegno costituzionale, en Riforme elettorali, M. LuCiANI y M. VOLPI (eds.), Roma-Bari, 1995, 97.

6 C. Lavagna, «Il sistema elettorale nella Costituzione italiana», Riv. trim. dir. pubbl. (1952): 849 ss. 
una sola lista mayoritaria», deniegan la representación a las minorías, serían en contraste con: a) el artículo 1, debido a que tienden «mantener al gobierno quienes ya están en ello», haciendo «democracia aparente, en contra de todos los principios de continuidad y eficacia democrática»; b) el artículo 3, apartado 2, porque impediría «a priori la participación» a la organización política del país por «amplios sectores sociales»; c) el artículo 49, porque impediría «a todos los grupos políticos, excepto uno, intervención en la dirección de la voluntad política parlamentaria» ${ }^{7}$.

Los sistemas de mayoría «relativa» -en los que hay colegios (uninominales o plurinominales)- serían contrarios a los artículos 5 y 67 , porque, admitiendo la presencia de minorías «solamente, o principalmente, bajo el supuesto de diferenciaciones políticas locales», el Parlamento funcionaría en violación del «principio de unidad nacional, de la non distinción geográfica de las Asambleas»y y de prohibición de mandato imperativo ${ }^{8}$.

A continuación, Carlo Lavagna había argumentado que la Constitución exige que las minorías políticas estén representadas y que no haya proporcionalidad en la representación. En particular parece llamar a un sistema proporcional el principio de igualdad en el voto contenido en el artículo 49, apartado 2, que debe leerse a la luz del artículo 3 apartado 2. No se debe por lo tanto interpretar con el fin de garantizar sólo la «igualdad formal de los electores en el proceso electoral» («conforme a la simple interpretación histórica»), sino también la «igualdad sustancial, real y efectiva», que involucra el sistema electoral (entendido como el mecanismo de transformación de los votos en escaños) $)^{9}$.

La posición de Lavagna, a pesar de haber encontrado consenso entre los expertos constitucionales, siguió siendo minoritaria ${ }^{10}$. Un examen de la

7 C. Lavagna, Il sistema elettorale, cit., 855 ss.

${ }^{8}$ C. Lavagna, Il sistema elettorale, cit., $861 \mathrm{~s}$.

${ }^{9}$ C. Lavagna, Il sistema elettorale, cit., 868 ss., especialmente 871.

10 Sobre la ilegitimidad constitucional de los sistemas mayoritarios han hablado: A. Reposo, La forma repubblicana secondo l'art. 139 della Costituzione (Padoval, 1972), 113 ss.; G. FERRARA, Il Governo di coalizione (Milano, 1973), 54 (se deriva implícitamente de la afirmación de que el «valor constitucional» de la «representación analítica de la realidad de la comunidad», implícita en el artículo 2 de la Constitución, es «alcanzable sólo a través de un sistema proporcional»); Id., Democrazia e Stato del capitalismo maturo. Sistemi elettorali e di governo, en Dem. dir. $4-5$ (1979), 513 ss.; G. Ambrosini, Introduzione a Costituzione italiana, LXIII (Torino, 1975); E. Bettinelli, Concorso dei cittadini alla determinazione della politica nazionale, partiti politici e referendum, en Referendum, ordine pubblico, Costituzione, E. BetTinelli y L. Boneschi (eds.) (Milano, 1978), 63 ss. (también en <http://www.radioradicale.it/referendum-ordine-pubblico-costituzione7-concorso-dei-cittadini-alla-determinazione-della-politica-nazionale-partiti-politici-e >); F. Lanchester, Sistemi elettorali e forma di governo (Bologna, 1981), 239-40; G. ConTINI, Democrazia, partecipazione, rappresentatività, en Individuo, collettività e Stato. Momen- 
literatura ha destacado, incluso antes de la transformación del sistema político italiano que tuvo lugar en los años noventa del siglo pasado, la tesis de la «neutralidad» de la Constitución en materia electoral que admite para la elección del Parlamento (y, en general, de los órganos de representación), no sólo sistemas proporcionales, sino también mayoritarios ${ }^{11}$.

Sin embargo, hubo quien -como Costantino Mortati, uno de los más grandes constitucionalistas italianos- argumentó que en el reconocimiento del derecho de los ciudadanos a participar, por medio de los partidos políticos, a

ti critici e processi evolutivi nelle democrazie occidentali e socialiste, I, F. LENTINI (ed.) (Palermo, 1983), 181 s.; T. MARTINES, sub art. 56, en Commentario della Costituzione, G. Branca (ed.), Le Camere, vol. I, Art. 55-63 (Bologna-Roma, 1984), 97; S. D'Albergo, Referendum: non toccate la proporzionale, en Rinascita 4, 4 de marzo de 1990; G.U. Rescigno, Democrazia e principio maggioritario, en Quad. cost. (1994), 223 (el Autor cree que son constitucionalmente ilegítimos todos los sistemas mayoritarios, pero los que atribuyen a una minoría electoral un número de escaños mayor que la mayoría absoluta); G. DossetTi, Costituzione e riforme, en Quad. cost. (1995), 272.

11 Véase F. PIERANDreI, Considerazioni giuridiche sulle ultime elezioni politiche italiane e sulle leggi ad esse relative, en Jus 1953, 353-357; G. BALladORE PALLIERI, La Costituzione italiana nel decorso quinquennio, en Foro pad. 1954, p. 41; U. ProsPeretTI, L'elettorato politico attivo, Milano 1954, pp. 158 s.; S. FuRLANI, entrada Elezioni politiche, en Nov. Dig. It., VI (Torino, 1960), 475 s.; ID., entrada Elezioni. I) Sistemi elettorali, en Enc. giur., XII (Roma, 1989), 4; L. PALADIN, Il principio costituzionale d'eguaglianza (Milano, 1965), 308, nota 154; M. Mazziotti di Celso, entrada Parlamento (funzioni), en Enc. dir., XXXI (Milano, 1981), 765; B. CARAVITA, M. LuCIANI, «Oltre la «democrazia bloccata»: ipotesi sui meccanismi elettorali», in Dem. dir. 1982, n. 6, pp. 120 ss.; G. DE VERGOTTINI, "Regole del gioco» e metodi decisionali più operativi, en Verso la riforma delle istituzioni, E. CuCCODORO (ed.) (Firenze 1983), 108; ID., «Dalle emendabilità alla «revisione totale» nella continuità della Costituzione», en Cinquantenario della Repubblica italiana, S. Labriola (ed.) (Milano, 1996), 239; D. Nocilla, entrada «Popolo, d) Diritto costituzionale», en Enc. dir., XXXIV (Milano, 1985), 366, nota 158; S. ORTINO, Diritto costituzionale. Storia ordinamenti teoria (Firenze, 1985), 244; G. PITRUZzella, entrada «Elezioni politiche: elettorato», en Enc. giur., XII (Roma, 1989), 4 y Forme di governo e trasformazioni della politica (Bari, 1996), 74; M. PEDRAZZA GorLERO, «Le riforme istituzionali per l'alternativa di governo», en La repubblica che non c'è, U. CURI y M. Pedrazza Gorlero (eds.), Milano 1993, 33 ss. y en Congetture costituzionali (Napoli, 2015), 295 ss. (de la que el testo es citado sucesivamente); C. FusARO, Le regole della transizione. La nuova legislazione elettorale italiana (Bologna, 1995), 29; V. ONIDA, Costituzione, cit., 14 ss.; ID., «La concezione della democrazia in Carlo Lavagna», en Il pensiero giuridico di Carlo Lavagna, F. LANCHESTER (ed.) (Milano, 1996), 142; ID., La Costituzione, cit., 128 s.; A. BARBERA, «Sistema elettorale e forma di governo in Carlo Lavagna», en Il pensiero giuridico, cit., 247; F. DONATI, «La revisione costituzionale», en La riforma della Costituzione nel progetto della Bicamerale, Padova 1998, 118; S. LABRIOLA, "Legge elettorale e ordinamento costituzionale: un rapporto complesso», en Scritti in onore di Giuseppe Guarino, II (Padova, 1998), 560; P. BARILE, Tra Costituzione e riforme. Scritti e interviste (1980-2000), R. CASSIGOLI (ed.) (Firenze, 2001), 127 s. 
la vida política nacional (artículo 49 Constitución), se requiere la legislación de sistemas electorales «limitativos de un sistema proporcional exasperado» $\mathrm{y}$ «con objeto de facilitar, con antelación a la votación popular, acuerdos de programa entre distintas formaciones políticas para el futuro gobierno de coalición $»^{12}$.

La Corte Constitucional, con algunas sentencias de los años sesenta, ha adoptado una posición que ha aparecido en línea con la actitud que prevalece entre los constitucionalistas. Dicha posición, en respuesta de una pregunta relativa a la elección de los gobiernos municipales, indicó el principio de igualdad de voto establecido por el artículo 48, apartado 2 de la Constitución. Esto significa que los electores están en una posición de «paridad perfecta» en la votación, «no siendo admitidos ni votos plurimos, ni múltiples», pero no se extiende «al resultado concreto de la voluntad del elector», que depende «exclusivamente por el sistema que el legislador, al no tener las disposiciones establecidas en la Constitución, ha adoptado para las elecciones nacionales y locales, en relación con las necesidades cambiantes que están vinculados a las consultas populares» ${ }^{13}$. Entonces, el legislador negó algún contraste al artículo 48, apartado 2 de la Constitución de los sistemas mayoritarios a las elecciones locales ${ }^{14}$. Por último, estableció que el artículo 48 tiene «carácter universal» y que «los principios establecidos deben ser observados en todos los casos en los que se ejerce este derecho» ${ }^{15}$.

\section{EL SISTEMA PROPORCIONAL EN LA PRIMERA FASE DE LA HISTORIA REPUBLICANA}

El sistema proporcional representó, durante la primera fase de la historia de la República, un elemento de la constitución «material» ${ }^{16}$.

12 Véase C. Mortati, Istituzioni di diritto pubblico, I (Padova, 1975), 461.

13 Sentencia $n .^{\circ} 43 / 1961$.

14 Véase, por ejemplo, en el caso de las elecciones municipales, la sentencia $\mathrm{n}^{\circ}$ 6/1963, n. ${ }^{\circ} 2$ de la Cons. in dir. Aquí, la Corte parece considerar esencial la representación institucional de la minoría. Para evitar que todos los escaños sean asignados a la lista ganadora debe tener por lo tanto un correctivo, a que se refiere la legislación.

15 Véase la sentencia 96/1968, n. ${ }^{\circ} 3$ del Cons. in dir. La doctrina ha considerado que la afirmación hecha por la Corte en relación con los sistemas electorales municipales también puede aplicarse a las de las Cámaras.

16 Véase E. CHELI, «La forma di governo italiana nella prospettiva storica», en Rass. parl. (1998), 293.

La proporción no sólo era la regla para la formación de la representación política nacional, sino que se aplicaba a todas las formas de representación institucional. La corrección de cierta importancia se proporciona sólo donde -pensemos en el Consejo Superior de la Magistratura- no hay ninguna necesidad de impedir el acceso a las instituciones de 
La «cultura proporcional», basada en los orígenes de la República, y largamente dominante en la continua heterogeneidad de la sociedad italiana ${ }^{17}$, ha significado que la atribución a todos los partidos políticos de una representación institucional proporcional a los votos se considerase crucial para el funcionamiento de las instituciones y de la misma democracia.

La aprobación en 1953 de la «ley engaño», que preveía la asignación de un premio sustancial a "grupos de listas asociadas» que habían alcanzado la mayoría absoluta de los votos válidos en la elección de la Cámara de Diputados, parece contradecir lo anteriormente expuesto ${ }^{18}$.

Sin embargo, el poco éxito electoral de los partidos del centro que habían pasado la ley después de un enfrentamiento parlamentario -no tuvieron premio de mayoría por unos pocos votos- determinó el fracaso de la ley que fue derogada un año después de su entrada en vigor ${ }^{19}$, y produjo el efecto de hacer inmutables las elecciones de las Cámaras en el régimen político que se constituyó después de la Segunda Guerra Mundial ${ }^{20}$.

Se trata, por lo tanto, de un obstáculo enteramente político, y su argumento de que los sistemas no proporcionales no sean admisibles en la Constitución ofrece una cobertura legal para una cuestión que es fundamentalmente política. Los sistemas electorales de las Cámaras no se pueden cambiar porque las condiciones políticas -sobre todo la presencia de una izquierda que queda excluida del gobierno nacional y que debe ser garantizada- no lo permiten.

No fue hasta los años ochenta -cuando el sistema político, una vez que la temporada de «solidaridad nacional» fue agotada, empieza a mostrar los signos de una crisis que empeora progresivamente hasta explotar en la próxima década- porque el «tabú en torno a la ley electoral» ${ }^{21}$ se aprobó y el debate sobre la reforma electoral, entrelazado con el de la reforma institucional, tuvo lugar «al aire libre».

los grupos expresivos de intereses puramente empresariales, localista, etc. No, por lo tanto, para excluir, sino para fortalecer la representación de las corrientes políticas y culturales en la sociedad. Véase G. Ferri, Magistratura e potere politico. La vicenda costituzionale dei mutamenti del sistema elettorale e della composizione del Consiglio Superiore della Magistratura (Padova, 2005), 25 ss. y 88 ss.

17 Cfr. T.E. Frosini, Le votazioni (Roma-Bari, 2002), 26 s.

${ }^{18}$ Sobre la ley n. ${ }^{\circ} 148 / 1953$ («Modifiche al testo unico delle leggi per l'elezione della Camera dei Deputati approvato con decreto Presidenziale 5 febbraio 1948, n. 26»), conocida como «ley engaño», véase, entre las publicaciones recientes, M.S. PIRETTI, La legge truffa, Bologna, 2003 y G. QuAGLIARIELlo, La legge elettorale del 1953 (Bologna, 2003).

${ }_{19}$ Véase la ley $\mathrm{n}^{\circ} 615 / 1954$.

${ }^{20}$ G. Amato, I sistemi elettorali in Italia: le difficoltà del cambiamento, Quad. cost. (1981), 527.

${ }^{21}$ G. AmAto, I sistemi elettorali in Italia, cit., 527. 
La resistencia de los partidos «históricos» en el cambio será aún más fuerte, ya que, a pesar de la dificultad comprensible de «adoptar nuevos enfoques» por grupos formados políticamente en un entorno proporcional y de la preocupación que las nuevas reglas electorales beneficien a los competidores, hay miedo a perder el poder.

Algunas iniciativas, como la de la Democracia Cristiana cercana a Mario Segni, indican que el clima está cambiando, y no parece distante el tiempo para la aprobación de nuevas leyes electorales que permitan a los ciudadanos ser protagonistas de la elección de las mayorías de gobierno.

El referendum del 9-10 de junio de 1991 que elimina la preferencia múltiple para la elección de la Cámara de Diputados (dejando a los electores la oportunidad de expresar su preferencia por un solo candidato $)^{22}$ demuestra que hay un deseo de cambio por parte de los electores y allana el camino para un cambio profundo de los sistemas electorales que va a pasar en la próxima legislatura.

\section{LOS SISTEMAS ELECTORALES MAYORITARIOS INTRODUCIDOS POR LAS LEYES N $276 \mathrm{Y} \mathrm{N}^{\circ} 277 / 1993$}

En un marco político que ya ha sufrido un cambio radical después de los acontecimientos de $1989^{23}$, con la desaparición del Partido Comunista Italiano, contra los que tuvo lugar la «conventio ad excludendum» ${ }^{24}$, y que está cambiando radicalmente para el efecto perjudicial de la acción del poder judicial contra la financiación ilegal de la política y la malversación en la administración pública, lo que determinará la disolución de los partidos de gobierno es el referendum del 18 de abril de 1993, el cual deroga el sistema electoral del Senado, marcando la transición desde sistema proporcional a mayoritario.

Las leyes n. ${ }^{\circ} 276 \mathrm{y} \mathrm{n} .^{\circ} 277 / 1993$, inspiradas en la ley electoral del Senado como resultado del referendum, pero haciendo algunas distinciones entre las

${ }^{22}$ Véase A. Chimenti, Storia dei Referendum. Dal divorzio alla riforma elettorale (Roma-Bari, 1993), 106 ss.; A. BARBera y A. Morrone, La Repubblica dei Referendum (Bologna, 2003), 124 ss.

${ }^{23}$ Véase R. DAHRENDORF, 1989. Riflessioni sulla rivoluzione in Europa (Roma-Bari, 1991).

${ }^{24} \mathrm{La}$ «situaciòn anomala del «caso italiano»»): así M. Pedrazza Gorlero, «Sviluppo economico e riforme istituzionali. Considerazioni introduttive», en Scienza e Cultura, 1990, pp. 333 s. y en Congetture costituzionali, cit., 239 s., que pone de relieve las consecuencias negativas de ese fracaso en el sistema político-institucional. El Autor recuerda apropiadamente que el Partido Comunista Italiano, «excluido de la dirección política principal», sin embargo, estaba «involucrado en la solución de importantes problemas económicos y políticos», ejerciendo tal vez una «influencia decisiva». 
Cámaras, dibuje un sistema mayoritario con un solo miembro de una sola vuelta electoral, moderado por la distribución de una cuarta parte de los escaños por representación proporcional y por un mecanismo de recuperación para las fuerzas políticas sin éxito en colegios particulares (disociación). Esto favorece la formación de dos grandes coaliciones que compiten por el liderazgo del país y permite al elector elegir la mayoría de gobierno ${ }^{25}$.

Hay por lo tanto una Constitución, la de 1948, que la doctrina ampliamente predominante considera «neutral» en materia electoral, sino que se ha redactado en un sentido proporcional. Algunas leyes electorales fueron escritas después de pasar por el principio de representación proporcional de la voluntad del pueblo, y a pesar no contener normas contrarias a los distintos artículos de la Constitución, parecen incompatibles con la estructura constitucional $^{26}$.

Esto plantea dos cuestiones.

La primera es: ¿La reforma electoral requiere la introducción de enmiendas a la Constitución y de normas legislativas que permiten la «salida de las urnas» por la mayoría para gobernar? En otras palabras: ¿Para completar la transición de una democracia consensual a una de alternancia, se necesita una reforma institucional que haga claramente una distinción entre las funciones de la mayoría y la oposición y que fortalezca la dirección política del gobierno? ${ }^{27}$.

La segunda cuestión es: ¿Demandas de reforma electoral que se hagan cambios a la Constitución y las leyes constitucionales con el fin de preservar las garantías constitucionales y, por lo tanto, limitar el poder de la mayoría? Por lo tanto, hay que elevar el quórum para la elección del Presidente de la República, los miembros «laicos» del Consejo Superior de la Magistratura,

${ }^{25}$ Véase, entre los demás, G. PAsquino, I sistemi elettorali (Bologna, 2006), 55 ss.

El nuevo sistema electoral se define de varias maneras por los académicos: G. PITRUZZELLA, sub art. 92, en Commentario della Costituzione, fundada por G. BRANCA e continuada por A. Pizzorusso, Il Consiglio dei Ministri. Art. 92-96 (Bologna-Roma, 1994), 232, lo define mayoritario «con medida correctiva proporcional»; C. AMIRANTE, Le procedure di revisione costituzionale, en I valori della Costituzione italiana, S. MAROTTA (ed.), (Napoli, 1996), 42 y A. REPoso, Lezioni sulla forma di governo italiana. Dalla monarchia statutaria al modello semipresidenziale (Torino, 1997), 105, lo definen «semimayoritario»; A. PIZzorusso, «I nuovi sistemi elettorali per la Camera dei deputati e per il Senato della Repubblica», en Riforme elettorali, cit., 130 e G. SARTORI, «Una occasione mancata? Intervista sulla riforma costituzionale», L. MorLINo (ed.) (Roma-Bari, 1998), 62, lo definen «mixto» (ese Autor añade «con carácter mayoritario»).

${ }_{26}$ Véase, en particular, M. PATrono, Maggioritario in erba. Legge elettorale e sistema politico nell'Italia che (non) cambia (Padova, 1995), 40 ss.

27 Véase M. PAtrono, Maggioritario in erba, cit., 43 ss. 
los jueces de la Corte Constitucional, de forma que no estén influenciados por la mayoría ${ }^{28}$.

En el buscar respuesta a la primera pregunta, se puede observar que la arquitectura constitucional, cuyo equilibrio se basa en la presencia de los órganos de dirección y de garantía, permite tanto un sistema político «consensual» como uno de «alternancia» (bipolar o bipartidista). Se puede, por lo tanto, considerar compatible con la Constitución tanto que la mayoría y la minoría -la dialéctica de la democracia parlamentaria- sean asociadas en las decisiones políticas, estableciendo una relación estable y un intercambio desigual que tiende a distorsionar las funciones del gobierno y de la oposición; tanto que, por el contrario, la mayoría y minoría ejercen respectivamente sus distintas funciones de dirección y de control, incluso revertiendo sus propias condiciones periódicamente, alternándose con intervalos más o menos regulares en el Gobierno ${ }^{29}$. Por lo tanto, no podemos decir que la Constitución de 1948 es un obstáculo para la afirmación de la democracia «gobernante», y que de la reforma mayoritaria del sistema electoral del año 1993 sea derivada la necesidad de un cambio constitucional destinado a reforzar los poderes la mayoría.

Esto no significa que el texto constitucional no tenga que ser mejorado mediante el fortalecimiento de los poderes de la mayoría y, al mismo tiempo, garantizando a las minorías un estatuto de la oposición, lo que sería apropiado para acompañar a la eventual revisión de la Constitución con un cambio de reglamentos parlamentarios. Tampoco se puede negar que el cambio en el sistema político y electoral, con la transformación de las elecciones desde una expresión de preferencia por un partido político (o movimiento), a

${ }^{28}$ Sobre la cuestión de la elevación del quorum para elegir órganos de garantía, véase, entre otros, S. CASSESE, Maggioranza e minoranza. Il problema della democrazia in Italia (Milano, 1995), 7 ss.; V. OnIDA, Costituzione, cit., 20 e 73 s.; L. EliA, Intervento, en Il pensiero giuridico di Carlo Lavagna (F. Lanchester ed.), (Milano, 1996), $303 \mathrm{~s}$.

${ }_{29}$ Sustancialmente en el mismo sentido D. Nocilla, «Brevi note su Costituzione e mutamento politico», in Multiformità e unità della politica, Atti del Convegno tenuto in occasione del $70^{\circ}$ compleanno di Gianfranco Miglio, 24-26 ottobre 1988, L. ORNAGHI y A. Vitale (eds.) (Milano, 1992), 351 s.; P. CIARLO, «Partiti in trasformazione e revisione della Costituzione», en Democrazia e forma di governo. Modelli stranieri e riforma costituzionale, S. GAMBINO (ed.) (Rimini, 1997), 108; A. MANNINO, «I rapporti tra la maggioranza e le opposizioni in Italia: dall'Assemblea Costituente all'entrata in vigore dei regolamenti parlamentari del 1971», en Il parlamento repubblicano (1948-1998), S. LABRIOLA (ed.) (Milano, 1999), 99 ss.

La distinción entre los dos tipos de sistemas políticos en el texto se expresa en la dicotomía entre democracias «consensuadas» (También llamado, cuando se quiere dar una connotación negativa al modelo, «asociativas») y las democracias «mayoritarias», que como se sabe - fue formulada por A. LiJPHART, Democracies. Patterns of Majoritarian and Consensus Government in Twenty-One Countries (New Haven-London, 1984). 
la que se concedía una «delegación en blanco», a una votación de investidura de la mayoría de gobierno, puede causar «tensión» en la Constitución formal. Pensemos, en particular, en el papel de Presidente de la República en la gestión de crisis de gobierno, en el poder de disolución del Parlamento, etc.

En cuanto a la segunda pregunta, una parte de la doctrina ha dado una respuesta afirmativa. En el supuesto de que el quorum requerido por la Constitución en caso votos especiales sea «típico de un régimen proporcional» ${ }^{30}$, se argumentó que, en presencia de un sistema mayoritario, se debe aumentar el quorum. En particular, tiene que ser aumentada la mayoría necesaria para la aprobación de las leyes de enmienda a la Constitución, a fin de evitar el riesgo de que la mayoría de gobierno se apropie de la facultad de revisión ${ }^{31}$. De esta manera, se acaba refutando la tesis - que, como visto antes, está aceptada por la jurisprudencia constitucional y por la doctrina- que la Constitución es «neutral» en materia electoral.

En cambio, podemos decir que, a pesar de ser «neutral», la Constitución no admite distorsión alguna de la relación entre votos y escaños. El artículo 138 contiene principios que parecen dar a entender dudas razonables sobre la constitucionalidad de los sistemas electorales que, mediante la asignación de la mayoría de dos tercios a un partido político o una coalición de partidos que representa un porcentaje menor de los votantes (o, mejor, a un partido o una coalición de partidos que obtuvo un porcentaje inferior a dos tercios de los votos válidos, especialmente si no haya alcanzado la mayoría absoluta, es decir la mayoría de votos que puede sacrificar la garantía de las minorías), evitan que las minorías promuevan el referéndum, y luego activen un mecanismo de defensa de las minorías mediante la resolución legislativa aprobada por la mayoría de Gobierno ${ }^{32}$. En particular, al disponer la aprobación

30 A. MaCCANICO, «Intervento», en Come modificare la Costituzione. La democrazia repubblicana fra riforme e garanzie, G. TORLONTANO (ed.), en Nuova antología (julioseptiembre, 1994), 15. En el mismo sentido, entre los demás, C. PINELLI, «Ancora Costituzione della Repubblica o repubblica senza costituzione?», en Studi parl. e di pol. cost. 1 (1995): 32. Más recientemente, véase L. TruCCO, Democrazie elettorali e Stato costituzionale (Torino, 2011), $523 \mathrm{~s}$.

${ }_{31}$ Sobre ese tema, véase G. FERRI, Il referendum nella revisione costituzionale (Padova, 2001), $178 \mathrm{~s}$.

32 De acuerdo con L. EINAUdi, Lo scrittoio del Presidente (1948-1955) (Torino, 1956), 22, está en contradicción con la Constitución «un premio que priva a sus minorías el derecho de oponerse efectivamente a las reformas de la Constitución»

En la literatura constitucional se expresan en el sentido constitucional de la ilegalidad de los sistemas electorales que asignan a los ganadores una mayoría de dos tercios de los escaños M. LuCIANI, Riforme elettorali e disegno costituzionale, cit., 100 y A. D'AloiA, «Dai voti ai seggi. Limiti costituzionali alla distorsione della rappresentanza elettorale», Rass. parl. (2014): 827. 
definitiva de las leyes de enmienda a la Constitución cuando se expresa a su favor una mayoría que también incluye una parte considerable de la minoría de la oposición, el artículo 138 establece el principio de garantía «interna» de la minoría. Permitiendo, además, un llamamiento al pueblo para proteger la misma minoría, dicho artículo establece el principio de garantía «externa» de la minoría. Si bien el principio de garantía interna pueda ser eludido gracias a una «recuperación» y al principio de garantía externa, el mismo no puede decirse del principio de garantía externa. Por lo tanto, no se puede impedir la aplicación del principio de garantía externa si la minoría no encontró tutela en el Parlamento ${ }^{33}$.

Se debería, por lo tanto, descartar la hipótesis que los nuevos sistemas electorales se hayan convertido en «tácitas revisiones»-como se afirma en la doctrina- a el artículo 138 de la Constitución, lo que debilita su «carácter garantista $\rangle^{34}$.

\section{LA LEY $\mathrm{N}^{\circ} 270 / 2005$}

El sistema electoral introducido en 1993 se mantuvo en vigor hasta la aprobación de la ley n. ${ }^{\circ} 270 / 2005^{35}$.

Algunos comentaristas han señalado que la nueva ley representa un regreso al pasado.

Sin embargo, si bien es cierto que con la votación de lista restableció el sistema proporcional, también es cierto que el premio de mayoría, convirtiendo la minoría más representativa en mayoría, dio un carácter claramente mayoritario a la ley electoral.

La ley electoral de 2005, por lo tanto, determina la transición de un sistema mayoritario a otro tipo de sistema de mayoría. Esto para satisfacer las necesidades -en parte convergentes, divergentes en parte- de los partidos de la mayoría de gobierno (Forza Italia, Alleanza Nazionale, Lega Nord, Unione di Centro y Nuovo PSI): a) contener la desproporción entre votos y escaños, lo cual es típico de los sistemas mayoritarios, pero puede llegar a ser muy alta en el caso de circunscripciones uninominales; b) permitir que cada uno se

\footnotetext{
${ }_{33}$ Véase G. FERRI, Il referendum nella revisione costituzionale, cit., 173 ss.

34 Véase G. Zagrebelsky, «Verso una iperdemocrazia plebiscitaria?», en Cinquant'anni di Repubblica italiana, G. NePPI Modona (ed.) (Torino, 1996), 246.

35 Sobre esa ley, véase, entre los demás R. BALduzzi y M. Cosulich, «In margine alla nuova legge elettorale politica», en Giur. cost. (2005), 5179 ss.; R. D'Alimonte y A. ChiARAMONTE, «Proporzionale ma non solo. La riforma elettorale della Casa delle libertà», Il Mulino 1 (2006), 34 ss.; G. TARLI BARBIERI, «I molti vizi e le poche virtù della nuova legge elettorale», en Dem. dir. 1 (2006), 29 ss.; C. FusARo, «La legge elettorale del 2005: profili ordinamentali e costituzionali», en Proporzionale ma non solo: le elezioni politiche del 2006, R. D’Alimonte y A. Chiaramonte (eds.) (Bologna, 2007), 89 ss.
} 
diferencie electoralmente de la lista opositora, marcando su identidad, sin alejarse de la lógica de bipolaridad; c) sustituir la competición dentro de las circunscripciones con una competición entre partidos; d) dar el poder para elegir los parlamentarios a los grupos de líderes de los partidos; e) garantizar una representación parlamentaria «autónoma» al partido más pequeño de la coalición (il Nuovo PSI). Esto con el objetivo preciso de limitar las pérdidas en caso de una derrota en las inminentes elecciones políticas -considerando una derrota muy probable, debido a que las encuestas predecían a una victoria clara para el centro-izquierda ${ }^{36}$.

La «caza» al premio -que consiste, por lo que pertenece a la Cámara de Diputados, en la asignación de escaños adicionales «hasta el umbral de 340 »- implica la formación de dos grupos que incluyen a todos los partidos, mucha parte de las cuales tiene acceso a la representación ya que los umbrales electorales se superan fácilmente.

Con referencia a la Cámara, la ley electoral prevé un umbral de $2 \%$ a nivel nacional para las listas de la coalición, la mitad de la prevista por la ley anterior, y no se aplica a la lista más votada entre los que no lo han alcanzado. En cuanto al Senado - cuya legislación electoral no prevé la concesión de un premio nacional, sino una multiplicidad de premios regionales (un premio en cada región italiana donde la coalición con el mayor número de votos haya obtenido el $55 \%$ de escaños $)^{37}$, el umbral es de $3 \%$ a nivel regional, pero puede ser evitado por los partidos más pequeños por acuerdos electorales, porque la ley permite implícitamente la presentación de listas conjuntas ${ }^{38}$.

El sistema electoral parece estar dispuesto de modo que favorezca el sistema multipartidista y, por lo tanto, una mayor fragmentación de la

${ }^{36}$ No se puede dejar de mencionar que la adopción de una enmienda a la ley electoral en contra de la voluntad de la oposición, persiguiendo intereses partidarios, constituye una falta grave, ya que las «reglas del juego» deben modificarse con el consentimiento de todos los «actores» o al menos la gran mayoría de ellos. Aunque hay que decir que el nuevo sistema, en realidad, no le importaba las partes menores del centro (en particular, a la Refundación Comunista, lo que podría conseguir escaños «propios» de la Cámara y el Senado, acceder a la autonomía), y el hecho de que hubo una obstrucción en el Parlamento es tal vez más de un signo de una actitud de las minorías no demasiado hostil a la modificación de la ley electoral.

${ }^{37}$ Un mecanismo irracional, lo de los premios regionales, que, dada la distribución territorial de la aprobación electoral, podría reforzar las partes que habían aprobado la ley $n^{\circ} 270 / 2005$. Véase, desde un sentido crítico, G. ZAGREBELSKY, «Una riforma del voto irrazionale e incostituzionale», en la Repubblica, 25 de octubre de 2005.

38 En 2006 Verdi, Comunisti Italiani y Consumatori Uniti se presentaron a las elecciones de la Cámara con tres listas distintas y con una única lista (llamada «Insieme con l'Unione») al Senado, la que obtuvo 4,1\% a nivel nacional. 
representación política, lo que hace más difícil la gobernabilidad: un «regalo envenenado», se podría decir, al futuro ganador.

Pero el hecho es que mientras que en las primeras elecciones en las que se aplica el nuevo sistema electoral el premio de mayoría en elección de la Cámara se asigna a las coaliciones de partidos que están muy cerca de la mayoría absoluta de votos ${ }^{39}$, en las elecciones de 2013 -cuando se afirma un nuevo movimiento político, el Movimento 5 Stelle, el cual recoge los consentimientos de más de un cuarto de los votos, rompiendo la bipolaridad-el premio se otorga a una matriz (el centro-izquierda) que llegó a menos del $30 \%$ de votos. Es un resultado que pone de manifiesto la irracionalidad de una ley que no preveía un umbral mínimo para la consecución del premio. Dicha irracionalidad se destaca aún más teniendo en cuenta de que el segundo puesto se tarda sólo 124 escaños (un poco más de un tercio de los a que tiene derecho el ganador $)^{40}$.

\section{LA SENTENCIA DE LA CORTE CONSTITUCIONAL N ${ }^{\circ} 1 / 2014$}

Con la sentencia . $^{\circ} 1 / 2104$, la Corte Constitucional declaró constitucionalmente ilegítimos los sistemas electorales de la Cámara y del Senado.

La Corte, vistas sus anteriores resoluciones, reiteró que la Constitución es «neutral» en materia electoral. No hay, en otras palabras, modelo de sistema electoral impuesto por la Constitución», ya que «deja a la discreción del legislador la elección del sistema más apropiado y eficaz en vista del contexto histórico».

El sistema electoral, sin embargo, «si bien constituye una expresión de la amplia facultad legislativa, no está libre de control». Es «siempre censurable en curso de juicio de constitucionalidad cuando sea manifiestamente irrazonable».

Según la Corte, la provisión de un «mecanismo de recompensa» que consiste en la asignación de una cuota adicional de escaños sobre la base de la adjudicación proporcional es compatible con la Constitución en dos condiciones: a) que persiga un objetivo de importancia constitucional; b) que se haga respetar el «vínculo del menor sacrificio posible de otros intereses y valores constitucionalmente protegidos».

Sobre el «mecanismo de recompensa» previsto por el sistema electoral de la Cámara, la primera condición debe ser satisfecha debido a que la legislación, en cuanto concebida para «facilitar la formación de una mayoría

39 En 2006 el centro-izquierda prevalece en las elecciones a la Cámara con el 49,81\%, mientras que en 2008 el centro-derecha gana el 46,81\%.

40 Según L. CANFora, La trappola. Il vero volto del maggioritario (Palermo, 2013), 9, fue el «mayor escándalo» de la «historia política italiana». 
adecuada en el Parlamento», tiene como objetivo el de «garantizar la estabilidad del gobierno del país» y «acelerar el proceso de toma de decisiones». La segunda condición no puede, sin embargo, ser satisfecha debido a la falta de señalamiento de un «umbral mínimo de votos por la lista (o listas de la coalición) de mayoría relativa». Esta circunstancia, distorsionando los límites de la relación entre votos y escaños, penaliza excesivamente otros intereses constitucionalmente relevantes y causa «una profunda alteración de la composición de la representación democrática, la que es la base de toda la arquitectura existente del orden constitucional».

Un premio de mayoría sin umbral mínimo se plantea, en concreto, en contraste con las siguientes disposiciones constitucionales: el artículo 1, apartado 2, debido a que la composición de la asamblea electa está demasiado lejos de la soberanía popular (es decir, la voluntad del pueblo expresada en las elecciones); los artículos 3 y 48, apartado 2, porque viola la igualdad del voto (que no exige al legislador ordinario la elección de un sistema en particular, pero todavía «requiere que cada voto haga una contribución potencial y eficaz a la formación de los órganos de elección» $\mathrm{y}$ «adquiere diferentes tonos en función del sistema electoral elegido»); con el artículo 67, debido a que el Parlamento, formado sobre una base que falsifica el voto popular, ya no sería el lugar de la representación política nacional.

En cuanto a los premios regionales, previstos por el sistema electoral del Senado, no podrá existir incluso la primera condición, debido a que el mecanismo con más premios es inadecuado para alcanzar el objetivo de garantizar la estabilidad del gobierno y la eficiencia en la toma de decisiones. De hecho, «tiene el efecto de que la mayoría en la asamblea del Senado sea el resultado aleatorio de una suma de premios regionales que pueden llegar a invertir el resultado obtenido a partir de listas o coaliciones de listas sobre una base nacional, favoreciendo la formación de mayorías parlamentarias que no coinciden en ambas Cámaras del Parlamento, a pesar de una distribución homogénea del voto».

Con esa resolución -que fue bien recibida por la mayoría de los expertos $^{41}$-, la Corte Constitucional ha «golpeado en el corazón» a la ley $\mathrm{n}^{\circ} 270$ del 2005, cambiando los sistemas electorales de mayoritarios en proporcionales, con la corrección causada por las barreras.

La operación «de demolición» de la Corte Constitucional se completó con el rechazo de las listas bloqueadas, que tienen un orden predeterminado e inalterable por los votantes.

${ }^{41}$ La sentencia $n^{\circ} 1 / 2014$ ha sido objeto de muchos comentarios, por parte de los constitucionalistas, de los que no es posible hablar aquí. Sin embargo, se puede remitir al Dibattito sulla sentenza della Corte costituzionale $n .1$ del 2014, dichiarativa dell'incostituzionalità di talune disposizioni della L. n. 270 del 2005, in Giur. cost., 2014. 
No obstante, la Corte Constitucional no ha indicado que las listas bloqueadas sean siempre ilegítimas. Lo que sin duda son ilegítimas, según la Corte, son las reglas especiales contenidas en la ley n. ${ }^{\circ} 270 / 2005$ que limita la libertad de los electores y contradice el principio democrático. De hecho, esta ley dispone que todos los miembros del Parlamento sean elegidos a través de listas bloqueadas; que las listas sean «largas», o sea que se compongan de una «lista de candidatos muy larga (en los distritos más poblados)», a quienes el votante «raramente conoce»; que sean aceptadas «candidaturas múltiples» (es decir, que cada candidato tenga la oportunidad de presentarse en varias circunscripciones), por lo que «la expectativa de elección con respecto a la misma orden de la lista puede ser decepcionada, teniendo en cuenta [...] el derecho del ganador a optar por otras circunscripciones sobre la base de las instrucciones del partido».

La disciplina censurada -observó la Corte- no es «comparable ni con otros sistemas que se caracterizan por listas cerradas solamente en una parte de los escaños, ni con otros grupos que se caracterizan por las pequeñas dimensiones territoriales, en los cuales el número de candidatos a ser elegidos es demasiado bajo para asegurar un conocimiento eficaz de la misma y con ello la eficacia de la elección y la libertad de voto (al igual que lo que sucede en el caso de las circunscripciones uninominales)».

Parecería, entonces, que para que la Corte Constitucional sean admisibles los sistemas electorales que asignan sólo una parte de escaños con listas cerradas y tal vez listas bloqueadas, a condición de que, sin embargo, el voto de la lista, por sus características concretas también pueda ser considerado como un voto a personas (pensemos, por ejemplo, en las listas de tres o cuatro candidatos - las dichas listas «cortas»- cuyos nombres están impresos en la tarjeta, lo que facilita a los electores «reconocer» a los candidatos) .

Según algunos, se trata de una decisión correcta también en este sentido. Ella expresaría una posición equilibrada, que no limita la discreción del legislador de forma inadecuada en un ámbito políticamente sensible, sino afirma que hay un nivel mínimo de libertad a ser protegido en la expresión de la votación: el votante debe estar habilitado para tomar una decisión que tenga en cuenta a la persona a ser elegido. El voto no puede quedarse reducido en el caso de una preferencia por un "partido en abstracto»" ${ }^{42}$.

Sin embargo, hay algunos expertos constitucionalistas que han mostrado preocupación ${ }^{43}$. Para ellos, deducir del artículo 48, apartado 2, la obligación

${ }^{42}$ Véase, por ejemplo, en este sentido, M. Pedrazza Gorlero, citado por G. Ferri, «I diritti politici dei cittadini e i sistemi elettorali delle Camere», en La democrazia costituzionale tra nuovi diritti e deriva mediale, G. FERRI (ed.) (Napoli, 2015), 107.

${ }^{43}$ Véase, entre los primeros comentarios de juristas en la presa, A. BARBERA, Intervista al Quotidiano Nazionale, 6 de dicembre de 2013 (a juicio del cual la corte se equivocò). 
del legislador al voto preferencial para el candidato sería arbitraria. En este sentido, se puede observar que el artículo 48, apartado 2, definitivamente requiere que cada elector tenga la oportunidad de expresarse sin interferencia al momento de votar, suponiendo que exista una pluralidad de opciones políticas (como puede verse en el resto del artículo 49). Libertad de voto, por lo tanto, significa sin duda libertad de elección entre varias listas, que están caracterizadas por un símbolo, y están formadas por candidatos. Un elemento personal es presente, por lo tanto, en el concepto de lista, y no se puede decir que el voto de la lista es un voto que no tiene por objeto las personas. Lo que es cierto que, cuando la lista es larga y hay candidatos en una circunscripción que simultáneamente tienen candidatos en otros grupos, se crea una situación muy problemática, ya que se fortalece el poder de las «secretarías» de los partidos y aumenta la distancia entre los votantes y candidatos, los cuales, por así decirlo, se convierten en «menos visibles», pero no hasta el punto de afirmar que estén oscurecidos y que, en última instancia, el elemento subjetivo desaparezca de la votación (¿el votante no tendría la oportunidad de ver los nombres de los candidatos no deseados en la lista y actuar en consecuencia? ¿O hay que aceptar las justificaciones del ciudadano que, después de la elección de personajes sospechosos, a los que él mismo contribuyó, dice: « ¿Yo voté por ese partido, pero no pudo evitarlo, ya que con las listas cerradas son «los dirigentes» de los partidos que deciden quién será elegido»?).

\section{LA LEY N ${ }^{\circ} 52 / 2015$ SOBRE LA ELECCIÓN DE LA CÁMARA DE DIPUTADOS («ITALICUM»)}

Porque de acuerdo con la jurisprudencia constitucional nacional el Parlamento no puede quedar sin un sistema electoral de aplicación inmediata, la decisión de la Corte no podía dejar un vacío.

La sentencia $n .^{\circ} 1 / 2014$, declarando inconstitucionales algunas partes de la ley n. ${ }^{\circ} 270 / 2005$, «mantuvo en pie» una legislación que prevé un sistema electoral proporcional con un escrutinio de lista y voto preferencial. Se trata de un sistema que no se adapta más a la situación de hoy, ya que la mayoría de fuerzas políticas representadas en el Parlamento están convencidas de que, para evitar el peligro de inestabilidad, se necesita una ley electoral que permita a los ciudadanos elegir la mayoría de gobierno.

Dado que no hay consenso suficiente para la introducción de un sistema mayoritario con distritos uninominales, la única solución era la de un sistema proporcional con un sistema de listas y el premio de mayoría. O, mejor dicho: un sistema electoral mayoritario caracterizado por un premio de mayoría, es

Véase otro comentario a la doctrina en, entre otros, V. OnIDA, Intervento en Dibattito sulla sentenza della Corte costituzionale n. 1 del 2014, cit. 
decir, un mecanismo que hace que la minoría popular más representativa se convierta en mayoría parlamentaria, dándole una cuota adicional de escaños. Esto, por supuesto teniendo en cuenta de la sentencia de la Corte.

La nueva ley electoral de la Cámara -la n. ${ }^{\circ} 52 / 2015$, conocida como «Italicum» ${ }^{44}$ - por lo tanto, proporciona un umbral mínimo de $40 \%$ de votos válidos para la consecución del premio, en el que la lista más votada obtendrá 340 escaños (el premio es, por lo tanto, la asignación de los escaños necesarios para llegar a este número). Los restantes escaños, salvo los destinados en el extranjero en virtud del artículo 56 de la Constitución, se dividen proporcionalmente entre listas minoritarias que han superado el 3\% de los votos válidos en todo el país, después de deducir los puestos atribuidos a Trentino Alto-Adige y Valle d'Aosta a los candidatos no estén relacionados con la lista ganadora ${ }^{45}$.

Sin embargo, ya que no hay garantía de que una lista llegará al $40 \%$ de los votos en la primera vuelta, se prevé una segunda vuelta en la que se enfrenten las dos listas más votadas en la primera vuelta. La lista más votada obtendrá 340 escaños.

La nueva ley electoral ha despertado en la doctrina constitucional, reacciones dispares.

Algunos han señalado que el umbral del $40 \%$ a pesar de constituir una mejoría con respecto a la situación anterior y al proyecto de ley aprobado en primera lectura por una rama del Parlamento (que preveía un umbral del $37 \%$ ), es demasiado bajo. Según ellos, constituye una distorsión inaceptable del principio democrático, en desacuerdo con la sentencia de la Corte, la que requiere que en el equilibrio de los intereses constitucionales no haya un sacrificio excesivo para la representatividad de las Cámaras. En cuanto a la posibilidad de segunda vuelta, hay dudas de constitucionalidad, ya sea porque no hay ninguna indicación de un umbral para acceder a ello. Por consiguiente, sería posible participar en dos listas fuertemente minoritarias, lo que resultaba en una competición «distorsionada», ya sea porque que no incluye ninguna condición para activar el premio (por ejemplo, con respecto al porcentaje obtenido por los beneficiarios). De esa manera, una fuerza política

${ }^{44}$ Sobre esta ley han hablado muchos expertos constitucionales. Dado el alcance limitado de este estudio, no es posible explicarlos por completo.

${ }^{45}$ Sobre las cuestiones problemáticas en la disciplina especial de estas dos regiones, véase L. Spadacini, «L'Italicum e alcune sue ulteriori criticità: la disciplina per Valle d'Aosta e Trentino Alto Adige, la distribuzione dei seggi tra i collegi e il differimento dell'applicazione della riforma», en Forum di Quad. cost. (2015). 
con un modesto nivel de consentimiento popular podría convertirse en mayoría de gobierno ${ }^{46}$.

Otros, sin embargo, creen que la ley no puede ser considerada como una falta de respeto de la información contenida en la sentencia n. ${ }^{\circ} 1 / 2014$. Es establecido, de hecho, un umbral mínimo para la adjudicación del premio, lo que le pedía expresamente a la Corte, para evitar lo que ocurrió en la Legislatura XVII. No hay datos precisos sobre el umbral previsto por la sentencia, la que establece un principio: lo que hemos visto en relación al equilibrio de intereses, lo que significa que la protección del valor de la gobernabilidad no puede dar lugar a un sacrificio desproporcionado para los demás (valores de la soberanía popular y de la representatividad de las asambleas elegidas). Si bien un umbral más alto puede considerarse preferible, no es que el $40 \%$ sería poco razonable, sino que probablemente es el mínimo indispensable ${ }^{47}$. En cuanto a la predicción de la segunda ronda entre las dos listas más votadas, ella representa la «tarjeta de reserva», la solución definitiva para asegurar, sin embargo, que se haya una fuerza política con una serie de grandes escaños suficientes para gobernar durante el período (aunque la estabilidad del Gobierno y la eficacia de su acción no puede ser garantizada por el sistema electoral). Puede pasar que una alta abstención, posiblemente junto con un gran número de votos en blanco y no válidos, condujera a asignar una mayoría de escaños en la Cámara a una lista representativa de una parte bastante limitada del electorado, mientras que se es preferible una mayoría de gobierno ampliamente legitimada por el voto popular. Sin embargo, la segunda vuelta, que prohíbe alianzas entre listas, está abierta a todos los elec-

${ }^{46}$ Esta opinión fue expresada por V. ONIDA, Una legge elettorale che non rispetta la reale maggioranza, en Corriere della Sera, 10 de marzo de 2015. Para ulteriores reflexiones críticas, véase, entre otros, M. VOLPI, «Italicum: un sistema anomalo e antidemocratico», en Costituzionalismo.it 1 (2015).

${ }^{47}$ En este sentido, durante el largo debate que ha anticipado la aprobación de la ley, M. AINIS, «Bene, con due dubbi», en Corriere della Sera, 21 de enero de 2014; P.A. CAPOTоSTI, «Le incognite della riforma alla prova delle Camere», in Il Messaggero, 21 de enero de 2014; A. PACE, «Intervista» en la Repubblica, 30 de enero de 2014; M. OLIVETTI, «Legge elettorale, prospettive di un'intesa», en Avvenire, 31 de enero de 2014; E. CHELI, «Intervista» en Il Messaggero, 13 de marzo de 2014; G. SILVESTRI, «Intervista» a la Repubblica, 23 de novembre de 2014. Según M. LuCIANI, «Intervista» a la Repubblica, 5 de marzo 2014, el umbral mínimo debería colocarse entre el 40 y el $45 \%$.

Entre los expertos que han comentado después de la entrada en vigor de la ley consideran razonable el umbral del 40\% S. CECCANTI, «L'Italicum come rimedio alla frammentazione», Nomos 3 (2015), en <http://www.nomos-leattualitaneldiritto.it/wp-content/ uploads/2016/01/I-pro-e-contro-Italicum_Nomos3-2015.pdf $>$ ); M. PEDRAZZA GorLERO, en I diritti politici dei cittadini e i sistemi elettorali delle Camere, cit., 111; G. SCACCIA, «La legge elettorale «Italicum» fra vincoli sistemici ed equilibri costituzionali», en Quest. giust. (2015), 17 ss. 
tores, y los que en la primera vuelta no se eran reconocidos en ningún de los dos candidatos, tienen una «segunda opción». Ellos deben elegir, entonces, no el candidato que es «más cerca», sino «el menos distante» como ocurre, por ejemplo, en la votación para la elección de los alcaldes (donde, sin embargo, se les permite hacer alianzas). Pueden renunciar al voto (por igual adversidad contra los contendientes, por convicción de la inutilidad del voto, etc.), pero lo que importa a los efectos de evaluar la constitucionalidad del mecanismo electoral, es que la ley les confiere la oportunidad para hacerlo, sin dejar de ofrecer un nivel aceptable de representatividad de las fuerzas que contribuyeron en la primera ronda ${ }^{48}$.

Las condiciones actuales del sistema político italiano, sin embargo, plantean preocupaciones legítimas sobre la adecuación de la votación, al menos con referencia a su marco legislativo.

El otro punto en el que es necesario que el legislador modifique la regulación anterior es el de las listas bloqueadas.

Cuando se descartó el sistema mayoritario con distritos uninominales, lo que garantiza mayor «visibilidad» de los candidatos y se asegura de que los votantes puedan tomar una decisión verdaderamente informada sobre las personas que los representarán -aunque hay que recordar que, desde este punto de vista, las leyes electorales de 1993 han tenido efectos desalentadores $^{49}$-, el problema podría ser resuelto mediante la liberación de las listas, es decir, que los votantes puedan siempre expresar, además del voto por una lista, la preferencia por uno o más candidatos.

Sin embargo, esta solución hubo resistencia por parte de los partidos, sobre todo en lo relativo a la necesidad de sus élites para retener el poder en la elección de los elegidos. Esta actitud no puede ser interpretada, como pasa a menudo, en términos exclusivamente negativos, asumiendo que el papel de los partidos políticos es lo de «representar intereses y seleccionar a grupos dirigentes $\rangle^{50}$.

Se ha encontrado así una solución de compromiso, con la disposición de listas parcialmente bloqueadas. De hecho, el bloque se aplica sólo a las cabeceras de listas de las 100 circunscripciones plurinominales en que se distribuyen los 20 distritos electorales. Las cabeceras de las listas serán así seguramente elegidas si la lista corresponde a un escaño, y esto debería

${ }^{48}$ Véase otra vez en este sentido, M. Pedrazza Gorlero, en I diritti politici dei cittadini e i sistemi elettorali delle Camere, cit., 111-2.

49 Las candidaturas en los colegios eran, de hecho, impuestas «desde arriba». Las direcciones nacionales de los partidos aliados se ponían de acuerdo sobre la distribución de candidaturas, descuidando el vínculo de los candidatos con el territorio.

${ }^{50}$ M. PEDRAZZa GORLERO, Le riforme istituzionali per l'alternativa di governo, cit., 300. 
asegurar un acceso en el Parlamento a la dirección de los partidos. Por lo que se refiere a todos los demás candidatos (es decir, los incluidos en la lista del segundo al último lugar, que puede coincidir con el tercer o el noveno, correspondiendo a cada circunscripción un número de colegios electorales no inferior a 3 y no superior de 9), los ciudadanos, en cambio, pueden expresar una preferencia. También se proporciona, a fin de equilibrar la representación de género, la posibilidad de expresar una preferencia distinta para un candidato de sexo diferente de aquel para el que se expresó la primera preferencia $^{51}$. Por lo tanto, serán elegidos, después de las cabezas de listas y «a la competencia de los escaños que pertenecen a cada lista en cada circunscripción, «los candidatos que hayan obtenido la mayoría de votos».

También en este caso la solución adoptada por el legislador ha dado lugar a evaluaciones contradictorias por los expertos.

Algunos han argumentado que no cumple con la sentencia n. ${ }^{\circ} 1 / 2014$ de la Corte Constitucional, o por lo menos que hay dudas al respecto ${ }^{52}$. De hecho, se exigiría -según una interpretación «rigurosa»- que las listas sean abiertas, porque sólo entonces podría recuperar la relación entre electores y elegidos, que es la piedra angular en la democracia. Aun admitiendo que sean permitidas otras soluciones, tales como listas semi-bloqueadas, debe tenerse en cuenta que el conjunto legislativo está aún demasiado orientado a favor del aparato del partido (con una penalización para los ciudadanos), ya que, según los cálculos llevados a cabo, los elegidos en la Cámara serán principalmente las cabezas de las listas indicadas por «secretarías»" ${ }^{53}$, para el beneficio de que sigue siendo la regla de que las cabeceras de lista pueden presentar su candidatura en diez colegios. Se trata -en opinión de muchos expertos- de una estafa para los electores, que contribuye a personalizar los partidos «a

51 Para ser aceptado, en la totalidad de los candidatos en cada lista de circunscripción, ninguno de los sexos puede ser representado en más de 50\%. Sólo para las cabeceras de las listas se podrán establecer excepciones a la restricción, alcanzando un máximo del $60 \%$ del mismo sexo en cada circunscripción.

52 Véase, entre los demás, L. CARlassare, «Danno democratico», disponible en $<$ http://www.libertaegiustizia.it/2015/08/17/legge-elettorale-danno-democratico/>; M. VILLONE, La legge 52/2015 (Italicum): da pochi voti a molti seggi, in Costituzionalismo. it 1 (2015); M. VolPI, Italicum, cit.

${ }_{53}$ Sin embargo, no se pueden hacer predicciones precisas. Sólo se pueden hacer hipótesis. Lo más probable, de acuerdo con uno de los mayores expertos de los sistemas electorales, es que la mitad de los candidatos será elegido con el voto bloqueado y otra mitad con la preferencia: véase R. D' ALIMONTE, "Candidati bloccati metà degli eletti», en Il Sole 24 Ore, 20 de enero de 2015 (que sostiene que el resultado dependerá esencialmente de «dos factores: el número y distribución de los candidatos múltiples y el número de colegios que uno o más partidos perdedores tendrán más de un escaño»). 
través de la atracción de nombres» de leaders ${ }^{54}$. No se puede, por lo tanto, considerar suficiente la prohibición de candidaturas múltiples para todos los candidatos sin cabeceras de listas.

Otros creen, sin embargo, que la solución dada por el legislador cumple por completo las «demandas» de la Corte Constitucional ${ }^{55}$. De hecho, el objetivo de su decisión es lo de establecer la ilegalidad de un sistema que, mediante la entrega del poder de elegir los miembros del parlamento en manos de pequeños grupos (de los cuales se dice a menudo, con tono polémico, que no fueron elegidos, pero «nombrados»), «estaba expropiando» los electores, que eran incapaces de expresar en términos concretos una preferencia para las personas. Se trata de un sistema que, despersonaliza totalmente la contienda electoral, debido a una combinación de una serie de factores (la presencia de listas largas, la exclusión de los votos, la posibilidad de candidaturas múltiples, utilizadas al extremo por algunos líderes políti$\cos ^{56}$, etc.), que no permite el establecimiento de una relación entre electores y candidatos. La nueva ley electoral, si bien no es un gran avance, modifica la situación anterior, mediante la introducción de una serie de medidas correctoras que en su conjunto personalizan el sistema de votación. Acordamos en el hecho de que crea una situación que no es ideal desde el punto de vista de la relación entre los electores y los candidatos, pero, a la luz de la sentencia $n .^{\circ} 1 / 2014$, se puede afirmar que cambia el marco jurídico de lo suficiente para ser compatible con la Constitución ${ }^{57}$.

${ }^{54}$ Véase V. OnIDA, «Intervista» en Il Sole 24 Ore, 1 de mayo de 2015, cuya valuación sobre la nueva ley electoral es «definitivamente» negativa. El número de diez es considerado «excesivo» incluso por los expertos que tienen opinión favorable: véase, entre otros, R. D'Alimonte, «Un sistema che assicura governabilità», en Il Sole 24 Ore, 11 de diciembre de 2014 y S. CECCANTI, "16 risposte alle 16 domande» en Il Sole 24 Ore, 3 de mayo de 2015 , en <http://www.huffingtonpost.it/stefano-ceccanti/ italicum-risposte-sole b 7199470.html>, que habla de un compromiso «negativo» pero «políticamente necesario» porque de lo contrario los partidos minores no habrían ninguna «certeza de la elección de su secretario».

Sobre el entramado entre candidaturas múltiples y voto de preferencia véase, en sentido crítico, R. D'Alimonte, «Il rischio di un pasticcio», en Il Sole 24 Ore, 3 de diciembre de 2014 y «I candidati plurimi e le preferenze», en Il Sole 24 Ore, 17 de enero de 2015. El mismo Autor ha destacado «asimetría» en «el hecho de que, mientras que el partido ganador tendrá una proporción significativa de los elegidos con preferencias, casi todos los perdedores entrarán en el Parlamento con el voto bloqueado» (véase R. D’ALIMONTE, «Ma l'Italicum non è a rischio», en Il Sole 24 Ore, 5 de febrero de 2015).

55 Véase, entre los demás, S. CECCANTI, «16 risposte», cit.

${ }^{56}$ Para un análisis crítico, véase M. AINIS, «Pluricandidati? Scelgano prima», en Corriere della Sera, 18 de enero de 2013.

57 Véase M. Pedrazza Gorlero, en I diritti politici dei cittadini e i sistemi elettorali delle Camere, cit., 114-5. 


\section{LA LEY ELECTORAL DE LA CÁMARA DE DIPUTADOS Y EL SENADO: ¿UNA POSIBLE SITUACIÓN DE INCONSTITUCIONALIDAD?}

La nueva ley electoral de la Cámara entró en vigor el 1 de julio de 2016. Ella nació, como hemos visto, por un fallo de la Corte Constitucional que contiene «principios» implementados con el modo más adecuado a las necesidades de los partidos, y, de hecho, sería ilusorio pensar que la más política de las leyes se puede hacer independientemente de la voluntad de las partes mismas, tal vez para satisfacer los deseos de una «sociedad civil que se cree, sin fundamento, mejor que su clase política $\rangle^{58}$.

La razón por la cual el legislador ha considerado oportuno posponer los efectos es que, en el momento de su aprobación, quedaba todavía por aprobar la ley de enmienda constitucional que, en el ámbito de una amplia reforma de la Parte II de la Constitución, convierte al Senado en un representante elegido de las instituciones locales, excluyéndolo de la relación fiduciaria. La Cámara de Diputados se quedaría, entonces, como único lugar de la «política»: el solo que puede dar o quitar la confianza en el Gobierno.

Cabe preguntarse qué podría suceder en el caso de que la revisión de la legislación de la Parte II de la Constitución -aprobada en segunda resolución con una mayoría absoluta, pero inferior a dos tercios- fuese rechazada por el referendum popular contemplado en el artículo 138 de la Constitución ${ }^{59}$, que fue solicitado por los parlamentarios (tanto los de la mayoría, como de la oposición) y por 500 mil electores y que tendrá lugar este año.

Nos encontraríamos con dos sistemas electorales muy diferentes, ya que el Senado sería elegido por el sistema resultante de la sentencia n. ${ }^{\circ}$ 1/2014 (llamado, en la jerga política y periodística, «Consultellum»): un sistema proporcional con la lista electoral y el voto de preferencia individual.

Esto podría plantear un problema. De hecho, el premio de mayoría, que -como se mencionó anteriormente- supone un sacrificio para la representación democrática, se puede justificar para la consecución de un objetivo 299.

${ }^{58}$ M. Pedrazza Gorlero, Le riforme istituzionali per l'alternativa di governo, cit.,

Para subrayar la politicidad de la ley electoral, véase T. E. FrosinI, Rappresentanza+ Governabilità=Italicum, 12 de mayo de 2015, en <http://www.confronticostituzionali. $\mathrm{eu} / \mathrm{p}=1434>$, quien opina que por eso se quita al sindicado la legitimidad constitucional.

Cabe destacar que la reforma electoral in itinere introduce un control preventivo sobre las leyes electorales. Véase, por último, S. CATALANO, «Il controllo sulle leggi elettorali: riflessioni sulla legge di revisione costituzionale approvata dal Parlamento che introduce il ricorso preventivo», en La democrazia costituzionale tra nuovi diritti e deriva mediale, cit., 173 ss.

${ }_{59}$ Véase G. FERRI, Il referendum nella revisione costituzionale, cit. 
constitucional significativo, como la estabilidad del Gobierno. ¿Pero cómo podría serlo si persiste igual bicameralismo con las dos cámaras relacionadas con el Gobierno por la relación fiduciaria, una de las cuales sólo se eligió con el sistema que contempla el premio de la mayoría?

Sin embargo, hay que recordar que nuestra Constitución, al establecer siempre que el Senado sea elegido "sobre una base regional» (artículo n. ${ }^{\circ} 57$ ), introduce un elemento de diferenciación de los sistemas electorales de las Cámaras, y parece ofrecer un argumento a favor de la legitimidad de la ley por las diferencias entre los sistemas. La doctrina admite pacíficamente, incluso a la luz de los diferentes programas aprobados por la Asamblea Constituyente en los sistemas electorales de la Cámara y el Senado ${ }^{60}$, que se puedan adoptar diferentes sistemas, y -como hemos visto- las leyes electorales siempre han presentado diferencias, no sólo por lo que se refiere al aspecto «regional». Podría haber, en principio, una diversidad también en cuanto a la fórmula electoral (es decir el mecanismo de procesamiento de votos en escaños para ser distribuidos entre los competidores electorales).

La hipotética situación sería muy inusual, y el legislador debería hacerse cargo e intervenir para eliminar un «anomalía». Por supuesto, se puede afirmar que la intervención del legislador sería políticamente oportuna, al fin de evitar un «lío». Sin embargo, no es claro si es legalmente necesario, habida cuenta de que los expertos italianos expresaron posiciones distintas sobre el tema. ${ }^{61}$

Si se encuentra con la situación contraria, es decir, en el caso en que la ley de la enmienda constitucional entrase en vigor, probablemente estaríamos frente a otro «lío»: el de la elección del Senado. No sería, de hecho, elegido con el sistema resultante de la sentencia $n .^{\circ} 1 / 2014$, sino de acuerdo con las disposiciones de la Constitución revisada.

Sin embargo, mientras que en el artículo 2, apartado 2 del texto revisado, se prevé la elección de senadores por los Consejos Regionales y los Consejos de las Provincias autónomas de Trento y Bolzano (por lo tanto, por elección

60 V. supra, $§ 1$.

${ }^{61}$ Para la tesis según la cual es constitucionalmente legítimo que, en un Parlamento con dos Cámaras con los mismos poderes, la legislación electoral atribuya un premio de mayoría solo a la Cámara de Diputados, véase, entre otros, R. D’ALIMONTE, «Sull’Italicum frenatori all'opera», en Il Sole 24 Ore, 22 de noviembre de 2014; A. BARBERA, «Intervista a la Repubblica», 23 de noviembre de 2014; R. D’ ALImonte y C. FusAro, «Un premio solo alla Camera? Un'opzione del tutto legittima», en Il Sole 24 Ore, 30 de noviembre de 2014; S. CeCCANTI, 16 risposte, cit. Para la tesis contraria, véase, entre otros, M. LuCIANI, Intervista a la Repubblica, 21 de noviembre de 2014; G. SILVESTRI, Intervista, cit.; M. AINIS, «Le nascoste imperfezioni dell'Italicum», en Corriere della Sera, 8 de noviembre de 2014 y «Il rompicapo perfetto disorienta i cittadini», en Corriere della Sera, 24 de noviembre de 2014; G. AzZARITI, «Intervista» en la Repubblica, 5 de mayo de 2015. 
indirecta), el artículo ${ }^{\circ}{ }^{\circ}$, párrafo 5 , establece que los senadores sean elegidos «de acuerdo con la decisión de los electores por los candidatos para consejeros en ocasión de la renovación de dichos órganos». Aquí está el problema: si «de acuerdo» significa que los consejos no tienen «elección independiente de los poderes, la elección no es una elección sino una ratificación». Si, sin embargo, los consejos «puedan tomar decisiones, es el cumplimiento que se contradice» ${ }^{62}$.

\section{OBSERVACIONES FINALES SOBRE LAS RECIENTES PROPUESTAS PARA LA MODIFICACIÓN DEL «ITALICUM»}

Los resultados de las elecciones municipales del 5 y 19 de junio 2016 confirman la tendencia «tripolar» del sistema político ${ }^{63}$, porque hay tres fuerzas principales que se reúnen y se dividen casi por igual la gran mayoría de los votos.

A los partidos tradicionales de centro-derecha y centro-izquierda, que se han alternado en el gobierno desde 1994, se ha añadido una fuerza política que puede aspirar a ganar las elecciones nacionales y, por lo tanto, a dirigir el país: el Movimento 5 Stelle.

El punto es que este movimiento, que representa aproximadamente el $30 \%$ del electorado, y no parece capaz de lograr en la primera ronda el premio de mayoría previsto en el «Italicum», sin embargo, tiene una fuerte capacidad de atracción en la segunda ronda. Esto ha sido demostrado por el hecho de que sus candidatos fueron ganadores en casi todas las segundas rondas para la elección de alcaldes, incluso cuando tenían un destacamento fuerte de los candidatos más votados en la primera vuelta.

El hecho de que la victoria del Movimento 5 Stelle en la próxima elección general ya no aparece como un evento remoto, sino como una posibilidad real, gracias al «Italicum» (que, como hemos visto, prevé una segunda vuelta entre las dos listas más votadas en el caso de que ninguna lista llegue al $40 \%$ de los votos en la primera ronda), ha abierto un debate sobre la modificación de la ley electoral de la Cámara.

${ }^{62}$ Véase G. ZAgrebelsKy, Intervento en la primera intervención pública del Comité por el No al referendum constitucional Renzi-Boschi, Roma, Sala della Regina di Montecitorio, 11 de enero de 2016 (disponible en el enlace <http://www.libertaegiustizia. it/2016/01/11/riforme-costituzionalila-posta-in-gioco/>).

El presidente de dicho Comité por el No, Profesor Alessandro Pace, en una carta enviada a los parlamentarios el 20 de noviembre de 2015, ha observado con dureza que una «formulación» así «críptica» es «indigna de una Constitución» (<http://www.libertaegiustizia.it/2015/11/21/riforma-costituzionalele-ragioni-del-no-lettera-ai-parlamentari/>).

${ }^{63}$ Véase supra, $\S 5$. 
Algunos han propuesto la eliminación de la segunda vuelta, proporcionando un único sistema de turnos ${ }^{64}$.

$\mathrm{La}$ atención hasta el momento se centró sobre la asignación del premio de mayoría, que, manteniendo la segunda vuelta, algunas fuerzas políticas (todo el centro-derecha, sino también Sinistra Italiana) querrían asignar a la coalición, en lugar de la lista, más votada ${ }^{65}$.

Este cambio facilitaría la alianza entre las fuerzas políticas de centroderecha y centro, porque cada partido, presentándose ante el electorado con su propio símbolo y su lista de candidatos, preservaría su propia identidad y «autonomía». Es posible prever también que si las partes del mismo grupo político, en lugar de presentar una lista única, se presentarán con varias listas obtendrán más éxito.

Sin embargo, la propuesta para cambiar el «Italicum» reemplazando el premio de mayoría a la lista por el premio de coalición es rechazada por el Movimento 5 Stelle, que considera como hostil el intento de cambiar el sistema de elección de la Cámara. De hecho, este movimiento, es el único que rechaza alianzas electorales con otras fuerzas políticas, y que no podría sacar ninguna ventaja por un sistema que favorece las coaliciones, incluso sufriendo para la presión para formar una alianza con otros partidos. En otras palabras, el Movimento 5 Stelle probablemente debería competir con dos opositores más fuertes y aumentar el riesgo de que se quede fuera de la votación.

Esta propuesta también parece encontrar la oposición de la mayoría del partido gobernante, el Partido Democrático, según el cual el premio a la coalición podría conceder demasiado poder a partidos pequeños, lo que les permitiría ejercer un papel desestabilizador. El temor -manifestado también por algunos expertos- es que se volvería a alianzas de gobierno «contenciosas y no homogéneas», «incapaces de gobernar», mientras que Italia, en un período muy difícil como el actual, se necesitarían mayorías cohesivas y gobiernos fuertes ${ }^{66}$.

El resultado de este debate sobre el cambio del sistema electoral no es todavía predecible.

${ }^{64}$ Una propuesta en dicho sentido ha sido formulada por la minoría del Partito Democrático: véase E. PATTA, «La sinistra Pd lancia il «Mattarellum 2.0», gelo di Renzi», en Il Sole 24 Ore, 20 de julio de 2016. También el Presidente emérito de la Republica Giorgio Napolitano apoya la abolición de la segunda vuelta, siendo que podría dar la victoria a un partito no demasiado representativo (véase Il Foglio Quotidiano, 20 de julio de 2016).

${ }^{65}$ Véase R. D' Alimonte, «Premio di coalizione per far saltare la «coerenza» dell'Italicum», en Il Sole 24 Ore, 3 de julio de 2016.

${ }^{66}$ Véase, entre las intervenciones más recientes, S. PAssigLI, «Perché l'Italicum va rivisto (ma senza peggiorarlo) », en Corriere della Sera, 4 de julio de 2016; ID., "Essenziale modificare l'Italicum per il futuro delle riforme», en Corriere della Sera, 30 de agosto de 2016 . 
Cabe destacar que una enmienda a la ley electoral que acaba de entrar en vigor es un tema políticamente sensible. Para abordar la situación se necesitaría un enfoque de largo plazo y la búsqueda de una mayor participación por las fuerzas políticas ${ }^{67}$. Es incorrecto cambiar las reglas electorales de acuerdo con las conveniencias ${ }^{68}$. La mayoría la opinión pública, probablemente, percibiría el cambio sobre algún punto concreto del «Italicum»-como, por ejemplo, lo de la segunda vuelta-como un acto de prepotencia dictado por el miedo a perder.

TITLE: The election of the Italian parliament: constitutional limits and political requirements

RESUMEN: El ensayo trata de los sistemas electorales de las Cámaras en la Italia Republicana. En la primera parte, de carácter histórico, se explican las razones por las cuales se adoptó inicialmente un sistema proporcional, que se mantuvo en vigor durante muchas décadas. Entonces, se exponen las razones que llevaron en 1993 a la transición a un sistema predominantemente de mayoría. La segunda parte trata de los acontecimientos actuales. A partir de la importante sentencia de la Corte Constitucional $n .^{\circ} 1 / 2014$, que declaró inconstitucional el sistema electoral de las Cámaras introducido por una ley de 2005, la ley $n .^{\circ} 52 / 2015$, que introdujo el nuevo sistema electoral de la Cámara de Diputados (Italicum). El ensayo termina con algunas reflexiones sobre el sistema de elección del Senado previsto en la reforma constitucional en curso y sobre la hipótesis de un nuevo cambio en el sistema electoral. Este cambio, según algunos, sería necesario porque el Italicum no es adecuado para el sistema político italiano actual, que se caracteriza por la presencia de tres grandes partidos políticos (Partito Democratico, Movimento 5 Stelle, y alianza de centro-derecha).

PALABRAS CLAVE: Parlamento italiano, sistema electoral, Constitución, partidos politicos, reformas

ABSTRACT: The essay deals with the electoral systems of the Chambers in Republican Italy. The first part of the essay offers an historical overview, explaining the reasons for which a proportional system was initially adopted, and remained in force for many decades. Subsequently, it sets out the reasons that led to the 1993 transition to a predominantly majority system. The second part deals with current events. Starting from the very important decision of the Constitutional Court n. 1/2014, which declared unconstitutional the electoral system of the Chambers introduced by a

${ }^{67}$ Véase M. OLivetti, «Riforma elettorale, oltre l'Italicum? Senza calcoli si può», en Avvenire, 4 de agosto de 2016.

${ }^{68}$ Véase G. PASQuinO, «L'Italicum non va bene ma il ballottaggio sì», en Corriere della Sera, 5 de septiembre de 2016. 
2005 Act, the Law 52/2015, which introduced the new electoral system of the Chamber of Deputies (the Italicum). The essay concludes with some reflections on the Senate election system, envisaged by the constitutional reform in progress, and on the hypothesis of a further change in the electoral system. This change, according to some, would be necessary since the Italicum is not be suitable to today's Italian political system, which is characterized by the presence of three major political parties (Democratic Party, Movimento 5 Stelle, and the center-right alliance).

KEY WORDS: Italian Parliament, electoral system, Constitution, political parties, reforms

RECIBIDO: 11.09 .2016

ACEPTADO: 24.10 .2016 